Japan. J. Med. Sci. Biol., 18, 311-316, 1965

\title{
ON RHABDOCHONA DASI SP. NOV. (THELAZIIDAE, RHABDOCHONINAE, RHABDOCHONA, RAILLIET, 1916) FROM A FRESH WATER FISH CALLICHROUS PABDA (HAMILTON)
}

\author{
UMAPATI SAHAY AND DEVENDRA PRASAD \\ Department of Zoology, Science College, Patna-5, India
}

(Received: October 14th, 1965)

\section{INTRODUCTION}

The family Thelaziidae was created by Railliet in 1916 to include a number of genera of the superfamily Spiruroidea parasitic in mammals, birds and fishes with Thelazia Bose., 1819, as the type genus. The genera Ceratospira Schneider, 1866 ; Cystidicola Fischer V. Waldheim, 1798; \& Oxyspirura Drasche, 1897 were subsequentally transferred by Railliet to this family. He also included genera Galeiceps, Schistorophus, Serticeps and Rhabdochona in this family.

In 1928 Travassos, Artigas and Pereira erected a new subfamily called Rhabdochoninae. They included three genera in the new sub family Rhabdochoninae, viz., Rhabdochona Railliet, 1916 ; Spinitectus, Fourment, 1883 and Cystidicola Fischer, 1798. The authors did recognize the fundamental similarity of structure among these genera besides their common property of being parasitic in the same group of hosts - the fishes. Only those forms were included in this that showed the following characters:

1. Bicuspid mouth with lips pronounced in some cases and rudimentary in others.

2. Pharynx, an elongated chitinised tube widened slightly anteriorly.

3. Two spicules unequal and dissimilar in length and in nature respectively.

4. Absence of a gubernaculum.

5. Presence of numerous pre- and post-anal papillae.

The genera Capillospirura Skrjabin, 1924 ; Metabronema Yorke and Maplestone, 1926 ; \& Comephoronema Layman, 1933 were regarded by Skrjabin as being related to Rhabdichoninae. Skrjabin admitted the validity of Rhabdochoninae but at the same time he vehemently protested the inclusion of Rhabdochoninae in the family Spiruridae Cerley, 1885 because of the morphological differences from Spirura Blanchard, 1849, the type genus of the family.

In 1946 he included all Spirurata of fishes (Showing thin delicate body, funnel-shaped oral cavity, elongated pharynx, cervical papillae present, double oesophagus, dissimilar and unequal spicules \& numerous postanal papillae.) into a new family Rhabdochonidae which consisted of three subfamilies viz., Rhabdochoninae, Cystidicolinae \& Spinitectinae. This attitude of including three subfamilies into the family Rhabdochonidae was adopted by Skrjabin in order to support and emphasize the host relationship between them.

1. Rhabdochoninae: Included two genera nemely Rhabdochona and Sterliadochona and were recognized by a smooth cuticle and non-filamented eggs.

2. Cystidicolinae: Included 5 genera namely Cystidicola, Capillospirura, Metabro- 
nema, Comephoronema and Pseudocystidicola Layman, 1933 and were recognized by filamented eggs.

3. Spinitectinae: Included a single genus - the Spinitectus and was recognized by a series of transeverse spined rings.

Choquette, 1951, however, didnot admit the validity of the characteristic used by Skrjabin, 1949 in his differentiation of the various families; for example polar filaments are present in some species of Rhabdochona and lacking in some species of Cystidicola. According to Choquette, Rhabdochoninae and Spinitectinae should be the subfamilies of Rhabdochonidae Skrjabin, 1946. Rhabdochoninae should include the genera with smooth cuticle viz., Rhabdochona, Sterliadochona, Cystidicola, Capillospirura, Metabronema, Compephoronema and Pseudocystidicola and Spinitectinae with a single genus Spinitectus.

The present paper gives an account of one species of the genus Rhabdochona Railliet, 1916 (Thelaziidae, Rhabdochoninae, Rhabodochona Railliet, 1916) collected from the intestine of a fresh water fish Callichrous pabda at Patna. Only a few of the large number of the fishes examined harbored these nematodes. Their incidence, therefore, appears to be poor. The number of the specimens recovered from one host was 3 females only and from other host two females and two males. The heads of the males were unfortunately crushed, while studying under the microscope.

\section{MATERIALS AND METHODS}

The fishes were cut open and a thorough examination of the alimentary canal and the whole body of the host was made. The nematodes were taken out, washed thoroughly in water and were fixed in hot $70 \%$ alcohol. The worms were finally preserved in $70 \%$ alcohol and glycerine solution. Lactophenol was found to be the best clearing agent. The study was made after fifteen days of the preservation. No permanent stained preparation of the specimens was made.

\section{DESCRIPTION}

These are small and slender bodied worms possessing extremities. Cuticle is devoid of transverse striations anteriorly and posteriorly but slight striation was marked on the middle region of the body. Head end presents a knob-like appearance. Excretory pore is invisible. The head is not separated from the body by a neck, The lips are not visible, either. The mouth leads into a pharynx divided into an anterior bell-shaped portion and a posterior tubular one, the two however not being distinctly separated by anything like constriction or depression. The walls of the pharynx are thick and chitinised. The bell-shaped portion of the pharynx measures $0.034 \mathrm{~mm}$ in length and $0.014-0.019 \mathrm{~mm}$ in breadth in the female. The tubular pharynx is relatively long and measures about $0.10 \mathrm{~mm}$ in the female worms. The oesophagus is divided into two parts, a smaller anterior muscular part and a long glandular part. The two portions measure $0.46 \mathrm{~mm}$ and $2.33 \mathrm{~mm}$ in length in the female worms.

The nerve ring encircles the muscular portion of the oesophagus and is $0.18 \mathrm{~mm}$ from the head end in the female. Cervical papillae seem to be four at the most anterior region of the head.

Male: The tail of the male measures $1.27 \mathrm{~mm}$, its tip being blunt and rounded. There are fifteen pairs of papillae on the tail, 11 being pre-anal and four post-anal in position. The pre-anal papillae are almost equidistant. The spicules are dissimilar in 


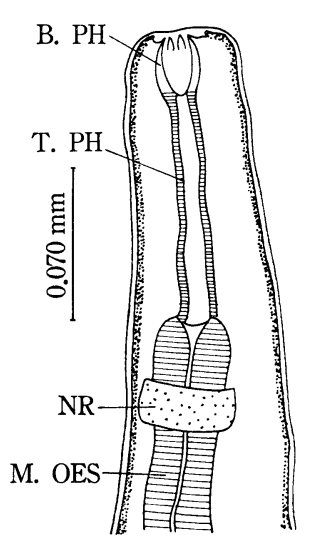

Fig. 1. Anterior end of female
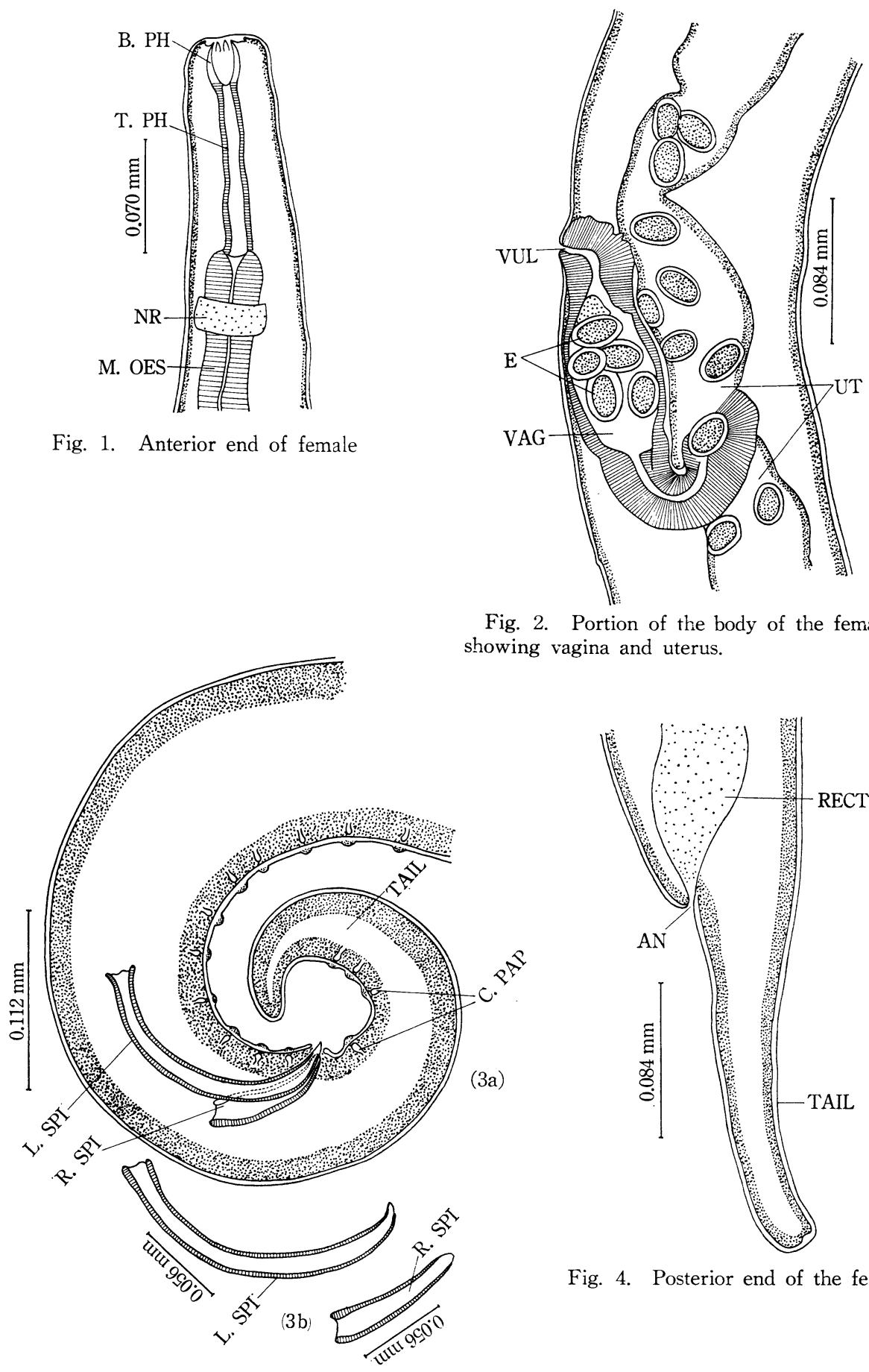

Fig. 2. Portion of the body of the female, shing vagina and uterus.

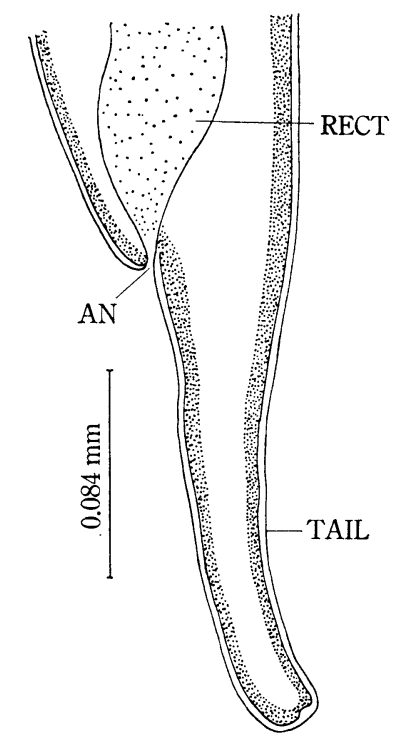

Fig. 4. Posterior end of the female

Fig. 3. (a) Posterior end of the male.

(b) Spicules of the male.

Abbreviation : RECT-Rectum ; AN-Aney ; TAIL-Tail ; L. SPI- Left Spicule ; R. SPI - Right spicule ; C. PAP - Caudal papillae; T. PH - Tubular portion of the phanynx; B. PH Bulb portion of the pharynx; M. OES-Muscular Oesophagus; N. R-Nerve ring; VUL-Vulva; VAG-Vagina; E-Eggs; UT - Uterus. 
shape and distinctly unequal in length. The right spicule is short, broad proximally, tapering gradually to a blunt pointed distal end and measures $0.098 \mathrm{~mm}$ in length, the left $0.21-0.27 \mathrm{~mm}$ in length. The caudal alae in the male are lacking.

Female: The female worms measure 10.5 to $11.4 \mathrm{~mm}$ in length, maximum width being $0.12-0.13 \mathrm{~mm}$. There are altogether four cervical papillae. Vulva is situated at a distance of $5.08 \mathrm{~mm}$ from the posterior end. The vulva is flushed with the body surface. The vagina runs posteriorly from the vulva forming a distinct U-shaped loop, one arm of which being slightly shorter. Vagina in turn is connected with the ovijector which gives origin to two uteri. The uteri are connected by short oviducts with the filamentous ovaries. The posteriorly placed ovary extends almost into the anal region of the body ending straight at the base of the rectum, but before doing so it forms a loop. The other ovary at the opposite end reaches the vicinity of the oesophagus. In the end it forms a loop before ending with its tip pointed anteriorly. The worms are oviparous, the uterus being heavily filled up with thick shelled eggs. The eggs measure $0.02 \mathrm{~mm}$ in width at the middle and $0.034 \mathrm{~mm}$ in length.

\section{DISCUSSION}

The genus Rhabdochona was created by Railliet in 1916 for Dujardin's worm Dispharagus denudata which forms the type of the genus. At present the genus comprises 38 species* of which 5 have been reported from India by Thapar (1950), Karve and Naik (1951) Ali (1956), Sahay and Prasad (1964) and Sahay (1965). The present worm differs from all the known species in the arrangement of the caudal papillae and the ratio of the spicule length in the male.

The worm in question resembles $R$. bosei (Sahay, 1965 in press) in having an equal number of caudal papillae, i. e., 11 pairs pre-anal and 4 pairs postanal. It however differs from $R$. bosei and $R$. kashmirensis (Thapar, 1950) in the spicule ratio and the nature of the spicule. The spicules in $R$. kashmirensis and $R$. bosei are bifurcated at the tips but in the worms recovered from Callichrous babda (Hamilton) this nature is not observed. The spicules in our worm tapers gradually to a blunt-pointed end. Besides the spicule ratio in the three species of worms i. e., $R$. kashmirensis (Thapar), $R$. bosei (Sahay) and $R$. dasi (Sahay \& Prasad) is $5: 1,3: 1$ and $2 \cdot 2: 1$, respectively. The eggs in $R$. dasi are not provided with polar filaments or cuticular projection. The males are not provided with the caudal alae.

The vulva divides the body length in the female in the ratio of $2: 1$ in the worm in

* (1) Disphargus denudata Dujardin, 1845 (2) R. acuminata Molin, 1860 ; Gendre, 1922 (3) R. turkestanica Skrjabin, 1927 ; Yorke \& Maplestone, 1926 (4) R. cascadilla Wigdor, 1918; Choquette, 1951 (5) R. gambiana Gendre, 1922 (6) R. macrolaima Gendre, 1922 (7) $R$. anguillae Spaul, 1927 (8) R. salvelini Fujita, 1927 (9) R. elegans Travassos, Artigas \& Pereira, 1928 (10) R. paski Baylis, 1928 (11) R. uca Pearse, 1933 (12) R. opiensis Hsu, 1933 (13) R. fortunatowi Dinnik, 1938 (14) R. conoura Linstow, 1885 ; Chitwood, 1933 (15) R. hellichi Sramak, 1901, Chitwood, 1933 (16) R. zacconis Yamaguti, 1935 (17) $R$. amago Yamaguti, 1935 (18) R. girellae Yamaguti, 1935 (19) R. gymnocrani Yamaguti, 1935

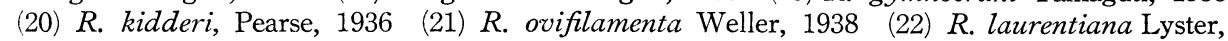
1940 (23) $R$. oncorhynchi Fujita, 1940 (24) R. jaenschi Jhonston \& Mawson, 1940 (25) R. tridentigeris Yamaguti, 1941 (26) $R$. coelorhynchi Jhonston and Mawson, 1945 (27) R. decaterensis Gustafson, 1949 (28) R. pellucido Gustafson, 1949 (29) R. cotti Gustafson, 1949 (30) R. euchilglansis Wu, 1949 (31) R. kashmirensis Thapar, 1950 (32) R. hospeti Thapar, 1950 (33) R. glyptothoracis Karve \& Naik, 1951 (34) R. sarana Karve \& Naik, 1951 (35) $R$, barbi Karve \& Naik, 1951 (36) R. singhi Ali, 1956 (37) R. mazeedi Sahay \& Prasad 1964 (38) R. bosei Sahay, 1965 (in press). 
question. In $R$. decaterensis (Gustafson, 1949) also the ratio is $2: 1$.

The occurrence of Rhabdochona species in the intestine of Callichrous pabda is a new record.

The worm in question here shows the following peculiarities :-

(1) Male with 11 pairs of pre-anal and 4 pairs of post-anal papillae.

(2) Spicule ratio in the male is $2 \cdot 2: 1$ with no bifurcation at the tip.

(3) Eggs thick shelled and without any ploar filaments or cuticular projection.

In view of the above discussion the authors feel justified in creating a new species for its reception. It is proposed to name the worm under reference as Rhabdochona dasi after Dr. S. M. Das, University Professor, University of Jammu and Kashmir, India.

The type speciemen of the species are deposited in the Helminthology Section of the Department of Zoology, Science College Patna-5, Bihar, India.

The authors express their thanks to Prof. S. M. Ali, Head, Zoology Department, Marthwada University, Aurangabad, India, Dr. S. Khera, Reader, Jodhpur University, India for their interest throughout the work. One of us (U. S) records his thanks to the authorities of the Council of Scientific and Industrial Research, New-Delhi for financial assistance. Thanks are also due to Mrs. Sarojani Narayan for the collection of the literature.

\section{REFERENCES}

ALI, S. M. (1956): Studies on the nematode parasites of the fishes \& birds found in Hydrabad state. Indian. J. Helm, 8, 1-87.

BAYLIS, H. A. (1956): Some parasitic worms mainly from fishes from lake Tanganyika. Ann. Mag. Natl. Histol. (10), 1, 552-562.

Baylis, H. A. (1939): The fauna of British India including Ceylon \& Burma. Nematoda Vol. III. Taylor and Francis Ltd., London.

Chitwood, B. G. (1933): A revised classification of the nematoda. J. Parasitol., 20, 104.

Chitwood, B. G. (1933): Changes in the generic position of certain nematodes of fishes formerly placed in the genus filaria. J. Parasitol., 20, 104.

Choquette (1948): Rhabdochona laurentiana lyster in Salvinilus frontinalis. Cann. J. Res. Ottawa., 26, D-209.

FujITA, T. (1927): On new species of nematodes from fishes of lake Biwa. Japan. J. Zool., 169-176.

FujITA, T. (1940) : Further notes on nematodes of Salmonoid fishes in Japan. Japan. J. Zool, 337-394.

Gustafson, P. V. (1949): Description of some species of Rhabdochona (Nematodes, Thelaziidae). Parasitology, 35, 534-539.

Jhonston, T. H. AND MAwson, P. M. (1940): Some nematodes parasitic in Australian fresh water fishes. Trans. Roy. Soc., South Australia., 64, 340-352.

KARVE, J. N. AND NAIK, B. G. (1951) : Some parasitic nematodes of fishes II., J. Univ. Bombay, Biol. Sci. n. s, 19, 1-37.

PeArSe, A. S. (1936): Parasites from Yucatan. Carnegie Inst., Washington Publication number 457, 45-59.

SAHAY, U. AND SINHA, D. (1964): On Rhabdochona mazeedi sp. nov. from the intestine of Eutropiichthys vacha Indian. J. Helm. Mach 17 (1 \& 2).

Spaul, E. A. (1927): On a new species of nematoda. Ann. Mag. Natl. Histol. Ser. 919, 636-641.

Thapar, G. S. (1954): Two new species of the genus Rhabdochona Railliet, 1916 from Indian fishes. Indian. J. Helminthol., 11, 535-540.

Weller, T. H. (1938) : Description of Rhabdochona orifilamenta n. sp. (Nematoda Thelaziidae). 
J. Parasitol, 24, 403-408.

YAMAGUTI, S. (1935): Studies on the helminth fauna of Japan part 9 (1) Nematodes of the fishes I. Japan. J. Zool 6, 337-38.

YAMAGUTI, S. (1941): Studies on the helminth fauna of Japan Nematodes of the fishes II. Japan. J. Zool., 9, 343-396.

Yamaguti, S. (1961): Systema Helminthum Vol. 3 Part I \& II, Interscience Publishers, INC. New York, London.

Yorke, W. AND MAPlestone, P. A. (1926; : The nematode parasites of the vertebrates. J-A. Churchill, London. 